\title{
Mass production of high-performance single atomic FeNC electrocatalysts via sequenced ultrasonic atomization and pyrolysis process
}

\author{
Jugang $\mathrm{Ma}^{1}$, Liguang Wang ${ }^{2}$, Yida Deng ${ }^{3}$, Weiwei Zhang ${ }^{1}$, Tianpin $\mathrm{Wu}^{2^{*}}$ and Yujun Song ${ }^{{ }^{*}}$
}

\begin{abstract}
Mass production of highly efficient, durable, and inexpensive single atomic catalysts is currently the major challenge associated with the oxygen reduction reaction (ORR) for fuel cells. In this study, we develop a general strategy that uses a simple ultrasonic atomization coupling with pyrolysis and calcination process to synthesize single atomic FeNC catalysts (FeNC SACs) at large scale. The microstructure characterizations confirm that the active centers root in the single atomic Fe sites chelating to the four-fold pyridinic $\mathrm{N}$ atoms. The identified specific Fe active sites with the variable valence states facilitate the transfer of electrons, endowing the FeNC SACs with excellent electrochemical ORR activity. The FeNC SACs were used as cathode catalysts in a homemade $\mathrm{Zn}$-air battery, giving an open-circuit voltage $(\mathrm{OCV})$ of $1.43 \mathrm{~V}$, which is substantially higher than that of commercial $\mathrm{Pt} / \mathrm{C}$ catalysts. This study provides a simple approach to the synthesis of single atomic catalysts at large scale.
\end{abstract}

Keywords: single atomic catalysts, ultrasonic atomization, oxygen reduction reaction, $\mathrm{Zn}$-air battery

\section{INTRODUCTION}

Energy conversion via electrochemical reactions for fuel cells has attracted increasing attention because of its advantages over traditional fossil energy sources, such as renewability, eco-friendliness, and high efficiency $[1,2]$. The oxygen reduction reaction (ORR) is a critical factor associated with electrochemical energy conversion in fuel cells. It is an important cathode reaction in many electrochemical energy conversion devices, including hydrogen fuel cells, direct methanol fuel cells, and metal-air batteries $[3,4]$. The main difficulty associated with the ORR is the sluggish multi-electron transfer process, which is typically catalyzed by precious metals such as $\mathrm{Pt}$, $\mathrm{Pd}$, or one of their alloys [5-7]. However, fuel cells still suffer from limited activity, poor stability, and poor durability, as well as the high cost and low natural abundance of the raw materials from which their components are made, impeding their sustainable commercial application [8-10].

Transition-metal complexes have been widely used in the physical and biological science, where they are essential in the catalysis, chemical synthesis, materials science, photo-physics and bioinorganic chemistry [11-13]. Since 1964, $\mathrm{N}_{4}$-macrocycles of non-noble metals (e.g., cobalt) based on the organometallic complexes and bionics have been developed as fuel cell cathode catalysts [14]. Various nonprecious earth-abundant metal catalysts, especially those based on transition metal-nitrogencarbon (MNC) compounds, have been continuously developed to address the issues related to the cost and earthabundant resources, and their catalytic performance has been gradually enhanced [15-18]. Meanwhile, recent studies on the surface chemistry, modified electronic structure, and optimal $\mathrm{O}_{2}$ adsorption related to such catalysts have led to MNCs with superior ORR performance [19]. Leonard et al. [20] compared MNC catalysts with various secondary nitrogen precursors to provide a more fundamental understanding of the origin of their catalytic reactivity. Ren et al. [21] used phenanthroline and cellulose filter paper as a nitrogen source and substrate, respectively, to prepare a Ni/N/C paper electrocatalyst with outstanding electrocatalytic activity toward the oxygen evolution reaction. However, in MNC studies, how to distinguish effective active sites has been a longdebated question because of interference from the various

\footnotetext{
${ }^{1}$ Center for Modern Physics Technology, School of Mathematics and Physics, University of Science and Technology Beijing, Beijing 100083, China

${ }^{2}$ X-ray Science Division, Argonne National Laboratory, 9700 S Cass Ave., Lemont, IL 60439, USA

${ }^{3}$ Tianjin Key Laboratory of Composite and Functional Materials, Tianjin University, Tianjin 300072, China

* Corresponding authors (emails: songyj@ustb.edu.cn (Song Y); twu@anl.gov (Wu T))
} 
components of the catalysts, whose compositions tend to be complicated. Recently, some experimental studies have demonstrated that $\mathrm{N}$-doped carbon substrates, single $\mathrm{Fe} /$ $\mathrm{Fe}_{3} \mathrm{C}$, or $\mathrm{FeN}_{x}$ molecules alone cannot preserve the high activity [22-24]. Some results have suggested that singleatom catalysts (SACs) provide not only the highest atom use efficiency but also identifiable active sites, providing a perfect model for both experimental and theoretical studies $[25,26]$. Thus, numerous SACs for electrochemical catalysis have been prepared using different pathways $[27,28]$, and some reasonable principles have been proposed for their design [25].

Even though numerous efficient MNC catalysts have been experimentally synthesized and/or theoretically designed, their commercial application has not yet been addressed for various reasons. First, precise parameter regulation is difficult to achieve for highly efficient catalysts and complex processes are difficult to control when scaling up the traditional processes, such as the sacrificial template, wet impregnation, and photochemical methods $[29,30]$. The exquisite structure and high performance of MNC catalysts require good control of a large number of chemical reagents and reaction parameters (e.g., time, temperature, pressure and mixing), presenting a formidable challenge in these conventional processes. Second, the overall cost of the as-prepared catalysts is no less than that of commercial $\mathrm{Pt} / \mathrm{C}$ catalysts. These costs include non-commercial fine chemicals, expensive processing equipment, and long synthesis cycles [31]. Furthermore, the additional issues associated with catalysts in fuel cells have not been addressed, such as oxygen transport, structural design, and optimization of the test conditions [32].

This study presents a simple strategy of ultrasonic atomization coupling with the control pyrolysis and acid leaching purification and the calcination for the preparation of bulk FeNC SACs with high catalytic performance toward the ORR. The simple synthesis method and the use of low-cost chemicals endow the FeNC SACs with great potential for rapid and cost-effective largescale synthesis. The $\mathrm{FeN}_{4} \mathrm{C}_{x}$ sites are identified as the main active sites by various methods used to characterize the microstructure and composition of a series of FeNC samples. With further acid leaching purification and a calcination treatment after the pyrolysis, FeNC SACs are formed into a golf-ball-like shape with a rough surface, offering a large contact area with more exposed active sites for enhanced mass diffusion of reactants. The electrochemical performance parameters of the FeNC SACs, including the positive half-wave potential $\left(E_{1 / 2}=0.87 \mathrm{~V}\right)$ and kinetic current density $\left(J_{\mathrm{k}}=10.44 \mathrm{mV} \mathrm{cm}^{-2}\right)$, are better than those of commercial $\mathrm{Pt} / \mathrm{C}$ catalysts. The synthesized FeNC SACs exhibit outstanding tolerance to methanol and high selectivity toward the ORR, indicating that they exhibit great potential for use in the cathode of direct methanol fuel cells. In particular, the long-term stability of the FeNC SACs is enhanced by the calcination step. Finally, we use the FeNC SACs as cathode catalysts in $\mathrm{Zn}$-air batteries, which exhibit greater capacity and a longer discharge time than batteries fabricated with commercial $\mathrm{Pt} / \mathrm{C}$ catalysts. Most importantly, this synthetic strategy provides a new general efficient method for the large-scale and low-cost synthesis of SACs for commercial applications.

\section{RESULTS AND DISCUSSION}

A sequenced multi-step process was used to prepare the FeNC SACs (Fig. 1). The $\mathrm{KOH}$ solution was nebulized into very small drops approximately $4-5 \mu \mathrm{m}$ in diameter (33-65 $\left.\mu \mathrm{m}^{3}\right)$ by an ultrasonic atomizer. These microdrops were sprayed into the $\mathrm{FeCl}_{2}$ solution at a rate of $1 \mathrm{~mL} \mathrm{~min}{ }^{-1}$ to form millions of microreactors, ensuring homogeneity of the synthesized $\mathrm{Fe}(\mathrm{OH})_{x}$ colloids (Reaction $\mathrm{S} 1)$. The $\mathrm{Fe}(\mathrm{OH})_{x}$ colloids and phenanthroline were then mixed with carbon black (CB) under stirring for $1 \mathrm{~h}$ to form iron precursors on $\mathrm{CB}$ (Reaction S2). The resulting mixture was further pyrolyzed for $2 \mathrm{~h}$ at $800^{\circ} \mathrm{C}$ under the $\mathrm{N}_{2}$ flow, forming FeNC SACs and some Fe nanoparticles (NPs) on the surface of the CB (this sample is denoted as FeNC, Reaction S3). The product was then immersed in $6 \mathrm{~mol} \mathrm{~L}^{-1} \mathrm{HCl}$ for enough time to leach the Fe NPs from the surface of the CB (this product is denoted as FeNC H, Reaction S4). A calcination step at

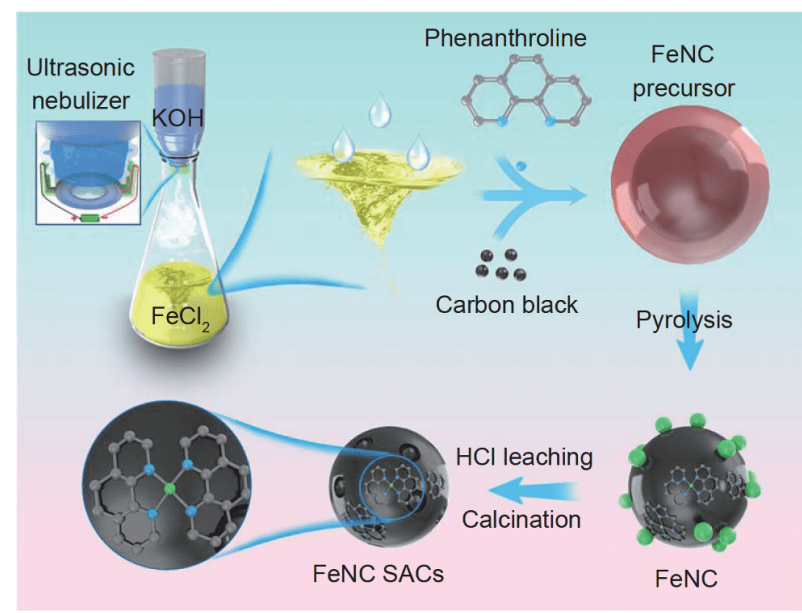

Figure 1 Schematic of the preparation of FeNC SACs by ultrasonic atomization in conjunction with pyrolysis and calcination. 
$800^{\circ} \mathrm{C}$ for $2 \mathrm{~h}$ was used to obtain the final golf-ball-like FeNC SACs (the product obtained after calcination at $400^{\circ} \mathrm{C}$ is denoted as FeNC H4). Owing to the simplicity and rapidness of this method, bulk production (more than $5 \mathrm{~g}$ ) was obtained in a single synthesis using our small lab equipment, as shown in Fig. S1; this process could be easily scaled to $\mathrm{kg} \mathrm{h}^{-1}$ using a large commercial atomizer. The detailed reaction mechanism associated with the synthesis steps is described in the Supplementary information.

The above analysis of the reaction mechanism was demonstrated by the transmission electron microscopy (TEM) and X-ray diffraction (XRD). The wide-view TEM image of the FeNC (Fig. S2) reveals that Fe NPs with different sizes are formed during the pyrolysis. As for the
FeNC SAC sample after the subsequent acid leaching and calcination, no Fe NPs are observed to be attached to the $\mathrm{CB}$, as shown in the typical wide-view TEM image (Fig. 2a), suggesting that the Fe NPs can be completely removed by the acid leaching step and the purified FeNC SACs can be obtained after the further calcination step. It is worth noting that $\mathrm{FeN}_{x}$ species were formed in the FeNC, as revealed by the appearance of peaks at $50.9^{\circ}$ and $74.9^{\circ}$ in its XRD pattern (Fig. 2b). After the acid leaching step, the XRD patterns (Fig. $2 b$ and Fig. S3) of the synthesized catalysts, including the samples FeNC H, FeNC $\mathrm{H} 4$ and FeNC SACs, show two distinct broad peaks at $24.5^{\circ}$ and $43.3^{\circ}$, which can be assigned to the (002) and (100) planes of graphitic carbon, respectively. The property and structure of $\mathrm{CB}$ can be measured by Raman
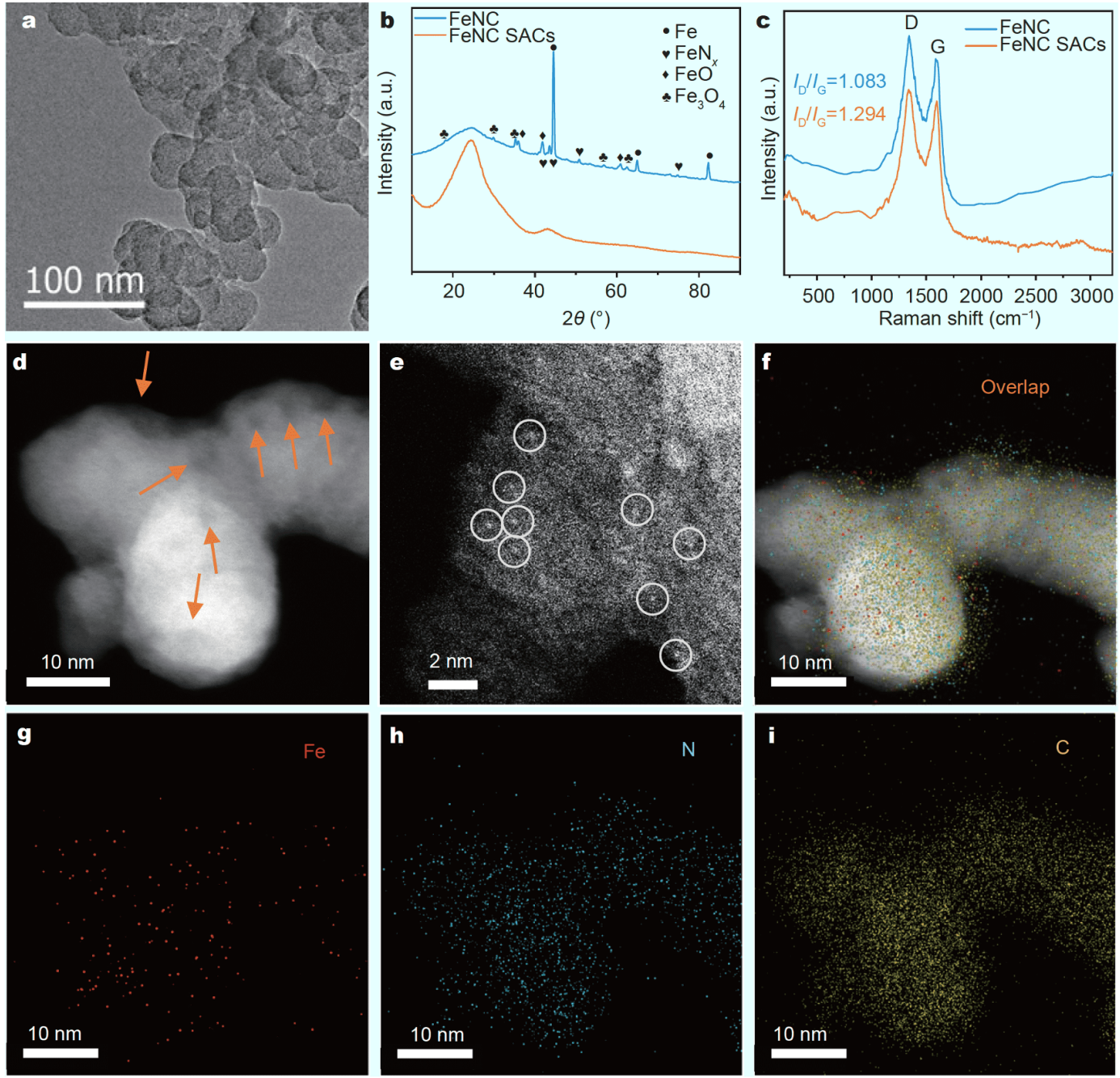

Figure 2 Microstructure characterization of the FeNC SACs. (a) TEM image; (b) Raman spectra and (c) XRD patterns for FeNC and FeNC SACs. (d) AC HAADF-STEM image showing the golf-ball-like structure of the FeNC SACs; (e) AC HAADF-STEM image with individual Fe atoms (bright dots). (f) The EDS image and the corresponding element mappings for (g) $\mathrm{Fe},(\mathrm{h}) \mathrm{N}$, and (i) C. 
spectrometer. As shown in the Raman spectra (Fig. 2c and Fig. S4), there are two clear peaks at 1340 and $1596 \mathrm{~cm}^{-1}$, corresponding to the D and $G$ bands of graphite, respectively. Clearly, the spectrum of FeNC SACs exhibits the highest peak intensity ratio $\left(I_{\mathrm{D}} / I_{\mathrm{G}}\right)$ of 1.294 among these FeNC catalysts (Fig. $2 c$ and Fig. S4). This result indicates that the defect concentration (arising from the $\mathrm{sp}^{3}$ hybrid in graphite) can be increased significantly in the partially graphitized $\mathrm{CB}$ by the acid leaching step and the following calcination at $800^{\circ} \mathrm{C}[33]$. Accordingly, the high-resolution TEM image (Fig. S5) shows that many hollow areas are present on the surface or the edge of the $\mathrm{CB}$ after the acid leaching and calcination, producing more defects (shown with arrows) as potential active sites.

Further characterization on the detailed morphology of the FeNC SACs (Fig. 2d) by aberration-corrected highangle annular dark-field scanning transmission electron microscopy (AC HAADF-STEM) reveals that the golf ball-like three-dimensional topology is finally formed with many cupped pits (arrowed points) on the surface or the edge of $\mathrm{CB}$, which can provide ample surface area for exchanging and transporting of the reactants and active sites during electrocatalysis. Furthermore, single Fe atoms (bright dots, some of them are circled in Fig. 2e) are displayed at the adjusted focus. Clearly, they are free of acid leaching and are homogeneously dispersed on the $\mathrm{CB}$, indicating that these $\mathrm{Fe}$ atoms should be anchored on the surface of $\mathrm{CB}$ with a certain way. The element mapping images (Fig. 2f-i) obtained by energy dispersive $\mathrm{X}$ ray spectroscopy (EDS) equipped onto HAADF-STEM reveal that the $\mathrm{Fe}, \mathrm{N}$, and $\mathrm{C}$ atoms are uniformly distributed in the FeNC SACs and the Fe atoms can achieve atomic dispersion on the surface of the CB. These results are also consistent with some previous results on the typical SACs [34,35], suggesting that FeNC SACs were successfully synthesized by our method.

Catalytic activity is directly affected by the contents of the key elements and the related valence state and electron status. To analyze the electronic status and valence of the key elements and the formed species in these catalysts, $\mathrm{X}$-ray photoelectron spectroscopy (XPS) was carried out. The survey XPS spectra (Fig. S6) reveal the presence of $\mathrm{Fe}, \mathrm{N}, \mathrm{C}$, and $\mathrm{O}$ in both the FeNC and FeNC SACs. The atomic ratios of the synthesized FeNC samples are summarized in Table S1, revealing Fe (total: 0.74\%) NPs are leached out and single $\mathrm{Fe}$ atom $(0.04 \%)$ are free from leaching. Meanwhile, the $\mathrm{N}$ content changed from $0.83 \%$ to $0.65 \%$, indicating most of $\mathrm{FeN}_{x}$ species are retained. Particularly, Fig. 3 shows the high-resolution XPS spectra of the Fe, N, O, and C of the FeNC SACs. A weak photoelectron $\mathrm{Fe}$ signal exists with lots of noise, which is clearly due to the low Fe content in the FeNC SACs. However, the high-resolution Fe $2 p$ spectra of the FeNC SACs (Fig. 3a) show Fe(II) peaks at 708.0 and $721.4 \mathrm{eV}$, $\mathrm{Fe}(\mathrm{III})$ peaks at 711.2 and $724.3 \mathrm{eV}$, and a particular $\mathrm{Fe}-\mathrm{N}$ signal at $703.4 \mathrm{eV}$, respectively [36]. The $\mathrm{N} 1 \mathrm{~s}$ spectrum (Fig. 3b) of the FeNC SACs shows one shoulder at $402.0 \mathrm{eV}$ and three distinct peaks at 400.8, 399.7, and $398.6 \mathrm{eV}$, which can be indexed to oxidized $\mathrm{N}$, graphitic $\mathrm{N}$, pyrrolic $\mathrm{N}$, and pyridinic $\mathrm{N}$, respectively. The fitting results indicate that the contents of the $\mathrm{N}$ types are $46.7 \%$ pyridinic $\mathrm{N}$ (or $\mathrm{Fe}-\mathrm{N}$ ), 37.7\% graphitic $\mathrm{N}, 12.4 \%$ pyrrolic $\mathrm{N}$, and $3.2 \%$ oxidized $\mathrm{N}$, respectively. The pyridinic $\mathrm{N}$ is $\mathrm{sp}^{2}$ hybridized, contributing one $\mathrm{p}$ electron to the $\pi$ system; while the pyrrolic $\mathrm{N}$ is $\mathrm{sp}^{3}$ hybridized, contributing two $\mathrm{p}$ electrons to the $\pi$ system [37]. The lone-pair electrons in the pyridinic $\mathrm{N}$ make the $\mathrm{N}$ atom more electronegative. Hence, the pyridinic $\mathrm{N}$ atoms in the FeNC SACs are very prone to chelating with positively charged Fe ions. The high-resolution $\mathrm{C}$ 1s spectrum of the FeNC SACs (Fig. 3c) shows four peaks at 289.5, 286.6, 285.4 , and $284.5 \mathrm{eV}$, which are assigned to $\mathrm{C}=\mathrm{O}, \mathrm{C}-\mathrm{O}$, $\mathrm{C}-\mathrm{N}$, and $\mathrm{C}-\mathrm{C}$ bonds, respectively.

The XPS spectra of oxygen in SACs are rarely analyzed in the previous literatures since complex interference of adsorbed oxygen and ambient oxygen $[38,39]$. However, it is very important for the evaluation of the electron states and/or the valence of the key elements and the conjugation types for highly efficient catalysts during the catalytic reaction. The high-resolution $\mathrm{O}$ 1s spectrum (Fig. 3d) is fitted by three peaks: (1) O-H possibly from bound water; (2) O-C possibly from the surface of the $\mathrm{CB}$, and (3) Fe-O possibly from the adsorbed oxygen by Fe sites. The $\mathrm{Fe}-\mathrm{O}$ peak is substantially weaker than that in the spectrum of the FeNC (Fig. S7), indicating that far fewer of oxygen atoms are adsorbed onto Fe sites in the FeNC SACs than those in the FeNC as there are many Fe NPs with easily oxidized surface Fe atoms in the FeNC. The mechanism of Fe-O formation in these catalysts will be further analyzed according to their X-ray absorption spectra (XAS, Fig. 4). Fig. S8 gives the XPS spectrum of the control sample without Fe source, showing a weak $\mathrm{N}$ signal and no $\mathrm{Fe}$ signal. This result indicates that phenanthroline cannot bond with $\mathrm{CB}$ at the absence of preformed $\mathrm{Fe}$ complexes as it can be self-decomposed during pyrolysis at high temperatures (e.g., $800^{\circ} \mathrm{C}$ ). That is, the final FeNC SACs can be anchored onto the surface of $\mathrm{CB}$ by covalent bonds in the subsequent pyrolysis treatment (Reaction S3) only if the $\mathrm{FeN}_{x}$ complexes are formed from 

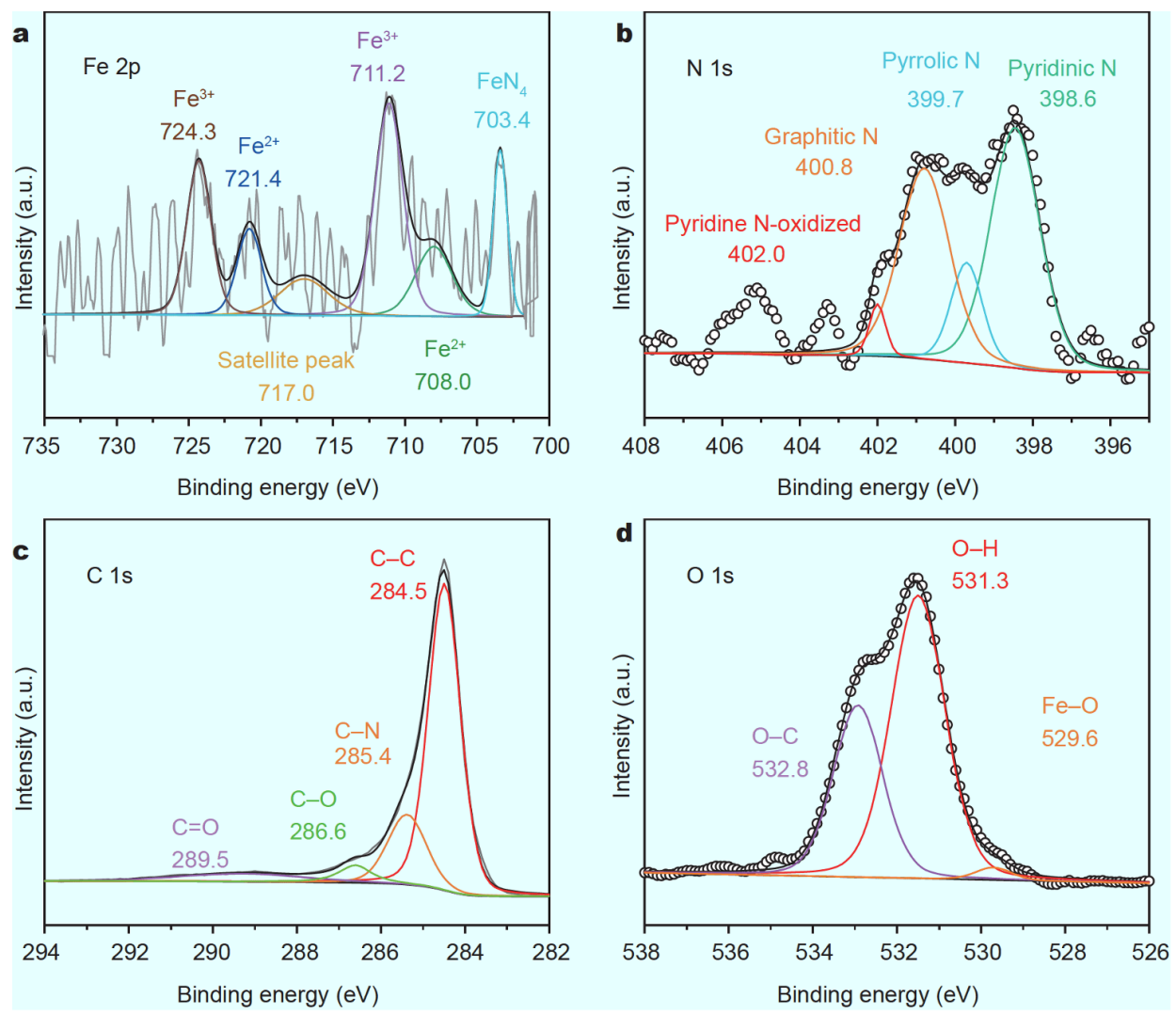

Figure 3 High resolution XPS spectra of the FeNC SACs. (a) Fe 2p; (b) N 1s; (c) C 1s; and (d) O 1s.

the pre-formed $\mathrm{Fe}$ precursors, indicating a synergistic effect between $\mathrm{N}$ atoms and $\mathrm{Fe}$ atoms forming the SACs tightly attached onto the CB.

Elemental iron itself has little activity toward ORR, which should be coordinated with other atoms (B, C, O, $\mathrm{N}$, etc.) to construct the active sites [40]. To further explore the electron state and the coordination environment of the single $\mathrm{Fe}$ atoms in FeNC SACs, X-ray absorption near-edge structure (XANES) and extended X-ray absorption fine structure (EXAFS) measurements were performed. Fe foil, $\mathrm{FeO}$, and $\mathrm{Fe}_{2} \mathrm{O}_{3}$ were used as standard samples to demarcate the fine structure of the Fe atoms of our samples. The resonance of the normalized XANES spectrum of the FeNC is similar to that of the Fe foil (Fig. 4a), indicating an abundance of $\mathrm{Fe}(0)$ atoms in the FeNC. This result is attributable to the reducing effect of carbon and phenanthroline during the high-temperature pyrolysis. The absorption edge of Fe atoms in the FeNC SACs is situated beyond those of the $\mathrm{Fe}$ foil and $\mathrm{FeO}$ reference but is close to that of $\mathrm{Fe}_{2} \mathrm{O}_{3}$ reference, indicating that the $\mathrm{Fe}$ atoms were in valence state of $3+$ after the acid leaching and the final calcination. Meanwhile, in the first- order derivatives of the XANES spectra (Fig. S9), the first maximum value of the FeNC SACs $\left(E_{0}=7126.7 \mathrm{eV}\right)$ is very close to the $E_{0}$ of $\mathrm{Fe}_{2} \mathrm{O}_{3}\left(E_{0}=7126.5 \mathrm{eV}\right)$, further confirming that the Fe atoms in the FeNC SACs mostly carry the positive charges (3+). Fe-ligand coordination is confirmed by the prominent absorption peak at $7114.5 \mathrm{eV}$, which is attributed to the $1 \mathrm{~s} \rightarrow 4 \mathrm{p}$ transition along with the simultaneous ligand-to-metal (L-M) charge transfer $[38,41]$. The theoretical spectra are consistent with the experimental results (Fig. 4b), suggesting a most possible structure that is an iron atom chelating to four pyridinic $\mathrm{N}$ atoms in the FeNC SACs (inset of Fig. 4b) [42].

Furthermore, the FT EXAFS spectrum (Fig. 4c) of the FeNC SACs shows a major peak at approximately $1.43 \AA$, which belongs to specific $\mathrm{Fe}-\mathrm{N}(\mathrm{O})$ bonding. Meanwhile, the strong $\mathrm{Fe}-\mathrm{Fe}$ bonding peaks of $\mathrm{FeNC}$ at 2.15 and $4.40 \AA$ almost disappear in the spectrum of the FeNC SACs, further revealing that Fe NPs were leached and that the Fe atoms existed as single-atom species in the FeNC SACs. The coordination number (4.3) of the first shell in the FeNC SACs, as obtained from the R-space spectrum 

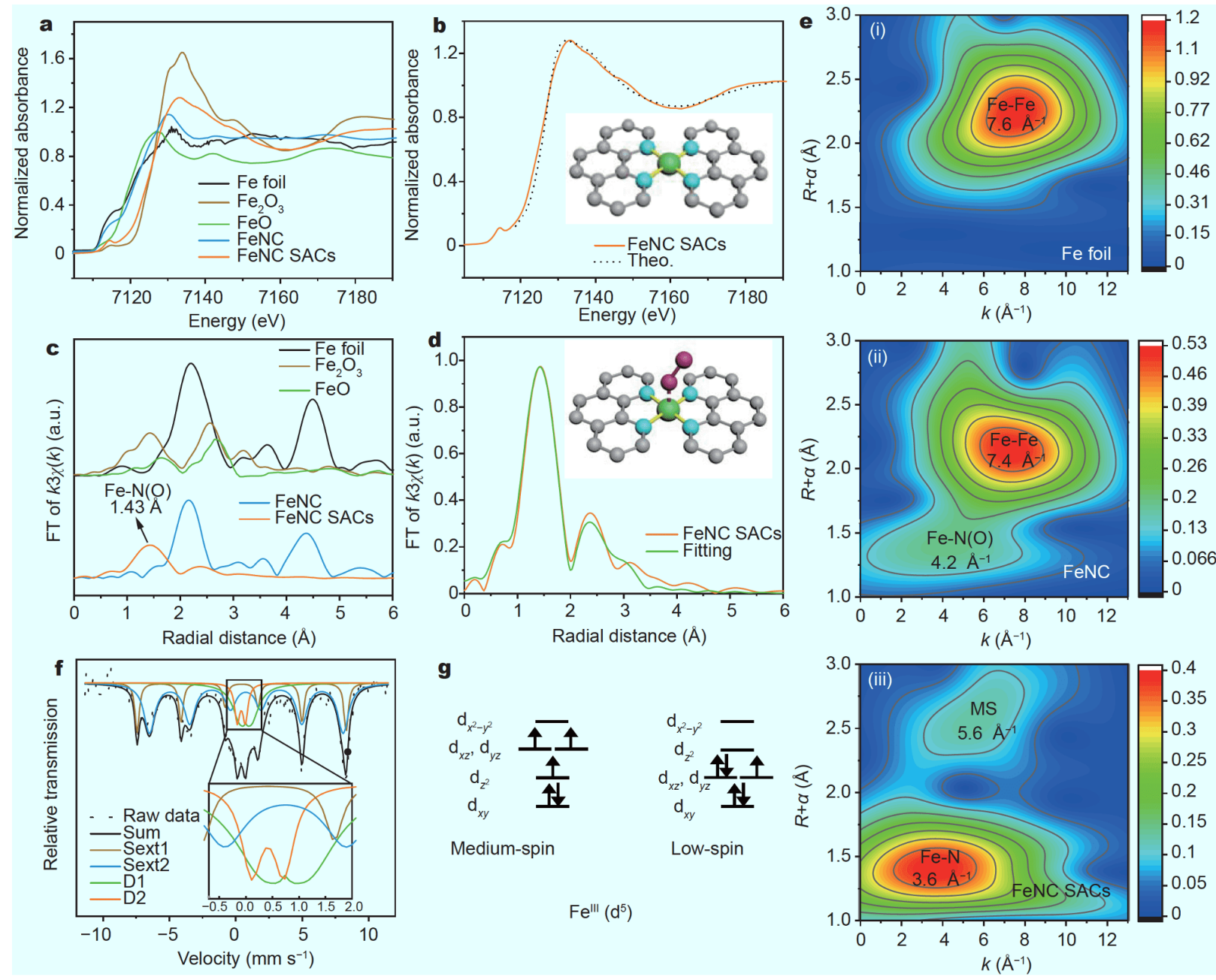

Figure 4 Atomic structural characterization. (a) Fe K-edge XANES spectra. (b) A comparison between the experimental XANES spectrum and a theoretical spectrum based on the structure of an Fe atom with four pyridinic $\mathrm{N}$ atoms bridging two graphene zigzag or armchair edges. (c) Fourier transforms (FTs) of the extended EXAFS spectra and (d) the corresponding EXAFS fitting curve for the FeNC SACs; the inset shows the proposed Fe$\mathrm{N}$ coordination environment (Fe (green), $\mathrm{N}$ (blue), C (gray), and O (purple)). (e) WT for Fe foil (i), FeNC (ii), and FeNC SACs (iii) samples, respectively. (f) Mössbauer spectroscopy characterization of ${ }^{57} \mathrm{Fe}$ and (g) the corresponding spin state of Fe(III).

fitting (Fig. 4d and Table S2), illustrates the $\mathrm{FeN}_{4}$ coordination structure in the FeNC SACs (inset in Fig. 4d), with an average $\mathrm{Fe}-\mathrm{N}$ bond length of $2.00 \AA$, consistent with the $\mathrm{Fe}-\mathrm{N}$ bond lengths reported elsewhere [38,42]. Meanwhile, the $\mathrm{Fe}-\mathrm{Fe}$ coordination number is as low as 1.2 (Table S2), indicating the extremely low content of $\mathrm{Fe}-\mathrm{Fe}$ bonding in FeNC SACs. Moreover, the X-ray absorption measurements of the catalyst performed under an air atmosphere suggest that $\mathrm{O}_{2}$ is reversibly adsorbed by the Fe centers (see the inset in Fig. 4d), which leads to the potential superior ORR activity [43].

Wavelet transform (WT) analysis was conducted to discriminate the backscattering atoms and provide high resolutions in the $\mathrm{k}$-space and the $\mathrm{R}$-space for evaluation of the possible coordination elements and the distance among key atoms. The maximum at approximately $3.6 \AA^{-1}$ in the WT contour plot of the FeNC SACs (Fig. 4e-iii) is attributed to the $\mathrm{Fe}-\mathrm{N}$ bonding contribution $[42,44]$. The low-intensity peak at $5.6 \AA^{-1}$ may be indexed to multiple scattering (MS). Because of the Fe NPs, the WT of the contour plot of the FeNC (Fig. 4e-ii) shows that the maximum intensity at $7.4 \AA^{-1}$ is similar to that of the Fe foil $\left(7.6 \AA^{-1}\right.$, Fig. 4e-i). Furthermore, a relatively weak Fe-N bonding peak is observed at $4.2 \AA^{-1}$, demonstrating that $\mathrm{Fe}-\mathrm{N}$ bonds were formed and reinforced during the pyrolysis and calcination steps, respectively.

To further elucidate the hyperfine interaction of $\mathrm{FeN}_{4}$ 
in the FeNC SACs, Mössbauer spectroscopy was used to characterize the electron configuration of FeNC SACs (Fig. S1). Here, benefit from the mass production of our method, more than $5 \mathrm{~g}$ of FeNC SACs can be produced in one single experiment, which is sufficient to attain highly reliable measurements based on FeNC SACs without using expensive ${ }^{57} \mathrm{Fe}$ isotope to be enriched. The Mössbauer spectrum of the FeNC SACs (Fig. 4f) is fitted with two main doublets (D1 and D2) and two secondary sextets (sext1 and sext2), and the Mössbauer parameters are summarized in Table S3. The positive values of isomer shift $\left(\Delta_{\text {iso }}\right)$ of doublets D1 and D2 reveal a decrease in the $4 \mathrm{~s}$ electron density, which can be a result of the increased screening effect by the $3 \mathrm{~d}$ electrons with a larger electron density [45]. The values of quadruple splitting $\left(\Delta E_{\mathrm{Q}}\right)$ doublets D1 and D2 are more than zero, indicating that the chemical environment of the iron nucleus and the occupation of their $3 \mathrm{~d}$ orbitals are different from the Fe standard sample. Moreover, the D1 and D2 doublets can be assigned to $\mathrm{FeN}_{4}$ structures that are possible in a graphene layer and/or are bridging two graphene zigzag or armchair edges with the Fe atoms in low-spin and medium-spin states (Fig. 4g), respectively [46]. According to crystal field theory and ligand field theory, this electron configuration of $\mathrm{Fe}$ atoms improves the catalytic activity and structure stability of the $\mathrm{FeN}_{4}$ in the FeNC SACs $[47,48]$. The two sextets on two sides correspond to inorganic Fe phases (i.e., $\gamma$-Fe or $\mathrm{Fe}_{3} \mathrm{C}$ ) $[20,34,49]$. Thus, on the basis of the aforementioned physical characterization results, the structure of the active site can be identified as $\mathrm{FeN}_{4} \mathrm{C}_{x}[24,50]$.

To evaluate the ORR performance of the as-prepared catalysts, rotating disk electrode (RDE) measurements in $\mathrm{O}_{2}$-saturated $0.1 \mathrm{~mol} \mathrm{~L}^{-1} \mathrm{KOH}$ were carried out. We compared the linear sweep voltammetry (LSV) curves for our catalysts (Fig. 5a) with those for commercial Pt/C catalysts (Figs S10-S15). The FeNC catalysts exhibit the highest limited current density, which can be attributed to the rough and large areas caused by the Fe NPs. The FeNC SACs exhibit the highest half-wave potential of $0.87 \mathrm{~V}$ in comparison with the FeNC $(0.85 \mathrm{~V})$ catalysts and the commercial $\mathrm{Pt} / \mathrm{C}$ catalysts $(0.84 \mathrm{~V})$, indicating an enhanced ORR activity. The ORR performance of the obtained FeNC SACs in alkaline electrolyte exceeds many of the previously reported Fe-based ORR electrocatalysts up to now (Table S4). The FeNC SACs also have the highest kinetic current density $\left(10.44 \mathrm{~mA} \mathrm{~cm}^{-2}\right)$ compared with the FeNC catalysts $\left(7.80 \mathrm{~mA} \mathrm{~cm}^{-2}\right)$ and the commercial $\mathrm{Pt} / \mathrm{C}$ catalysts $\left(5.13 \mathrm{~mA} \mathrm{~cm}^{-2}\right.$ ) (Fig. $5 \mathrm{~b}$ and Fig. S16a). The electron transfer number $(n)$ was eval- uated from Koutecký-Levich (K-L, Equation (S1)) linear plots based on the LSV measurements, indicating a direct four-electron ORR electrochemical catalytic pathway of the FeNC SACs (Fig. S14, $n=4.08$ ) was achieved. The values of $n$ for the FeNC catalyst series and commercial $\mathrm{Pt} / \mathrm{C}$ catalysts are a little bit greater than 4 due to the catalyst capacity and the electrode morphology effects $[51,52]$.

It has been experimentally demonstrated that the $\mathrm{FeN}_{4}$ species and pyridinic $\mathrm{N}$ can promote the occurrence of a four-electron transfer pathway and enhance the ORR activity $[22,53,54]$. Clearly, the experimental results also confirm this previously proposed four-electron transfer pathway for enhanced ORR activity. Moreover, the density functional theory (DFT) results predicted that $\mathrm{Fe}$ pyridine- $\mathrm{N}_{4}$ species are situated at the top of the volcano relationship of ORR activity, revealing that the adsorption energies of $\mathrm{Fe}$-pyridine- $\mathrm{N}_{4}$ are suitable for the intermediates (i.e., $\mathrm{OOH}^{*}, \mathrm{O}^{*}$, and $\mathrm{OH}^{*}$ in an alkaline electrolyte) [25]. Therefore, it is proposed that the ORR proceeds through the following four elementary steps, which are usually employed to investigate the electrochemical catalysis mechanism of ORR on various materials:

$\begin{array}{ll}\mathrm{O}_{2}(\mathrm{~g})+\mathrm{H}_{2} \mathrm{O}(\mathrm{l})+\mathrm{e}^{-}+{ }^{*} \rightarrow \mathrm{OOH}^{*}+\mathrm{OH}^{-}, & \text {(Reaction 1) } \\ \mathrm{OOH}^{*}+\mathrm{e}^{-} \rightarrow \mathrm{O}^{\star}+\mathrm{OH}^{-}, & \text {(Reaction 2) } \\ \mathrm{O}^{\star}+\mathrm{H}_{2} \mathrm{O}(\mathrm{l})+\mathrm{e}^{-} \rightarrow \mathrm{OH}^{\star}+\mathrm{OH}^{-}, & \text {(Reaction 3) } \\ \mathrm{OH}^{*}+\mathrm{e}^{-} \rightarrow \mathrm{OH}^{-}+{ }^{*}, & \text { (Reaction 4) }\end{array}$ where ${ }^{\star}$ stands for an active site on the catalytic surface. 1 and $g$ refer to liquid and gas phases, respectively. Based on the above model, the possible catalytic mechanism of FeNC SACs towards ORR can be proposed accordingly. First, Fe(III) is in a high valence state in the FeNC SACs, and it can receive an electron from the cathode membrane fabricated by the mixing of catalyst with $\mathrm{CB}$ and Nafion with high conductivity. The valence state of Fe is then decreased, leading to the enhanced reducibility. Subsequently, two unpaired electrons in the ground state $\mathrm{O}$ atom of the oxygen molecule are equivalent to a double radical with higher oxidation, so the oxygen atom is easily adsorbed by the low valence $\mathrm{Fe} . \mathrm{O}_{2}$ reacts with $\mathrm{H}_{2} \mathrm{O}$ to form $\mathrm{OOH}^{\star}$, and an $\mathrm{OH}^{-}$is released into the solution after the $\mathrm{O}_{2}$ gains an electron (Reaction 1). Similar to the previous step, after the second electron is transferred from the cathode to $\mathrm{OOH}^{\star}$, one of the $\mathrm{O}$ atoms gains an electron to generate $\mathrm{O}^{\star}$ and an $\mathrm{OH}^{-}$(Reaction 2). Subsequently, two electrons are transferred to an $\mathrm{O}$ through an $\mathrm{Fe}$ site to generate two $\mathrm{OH}^{-}$with the participation of $\mathrm{H}_{2} \mathrm{O}$ (Reactions 3 and 4). After the above-mentioned processes, a direct 4-electron transfer ORR pathway is 

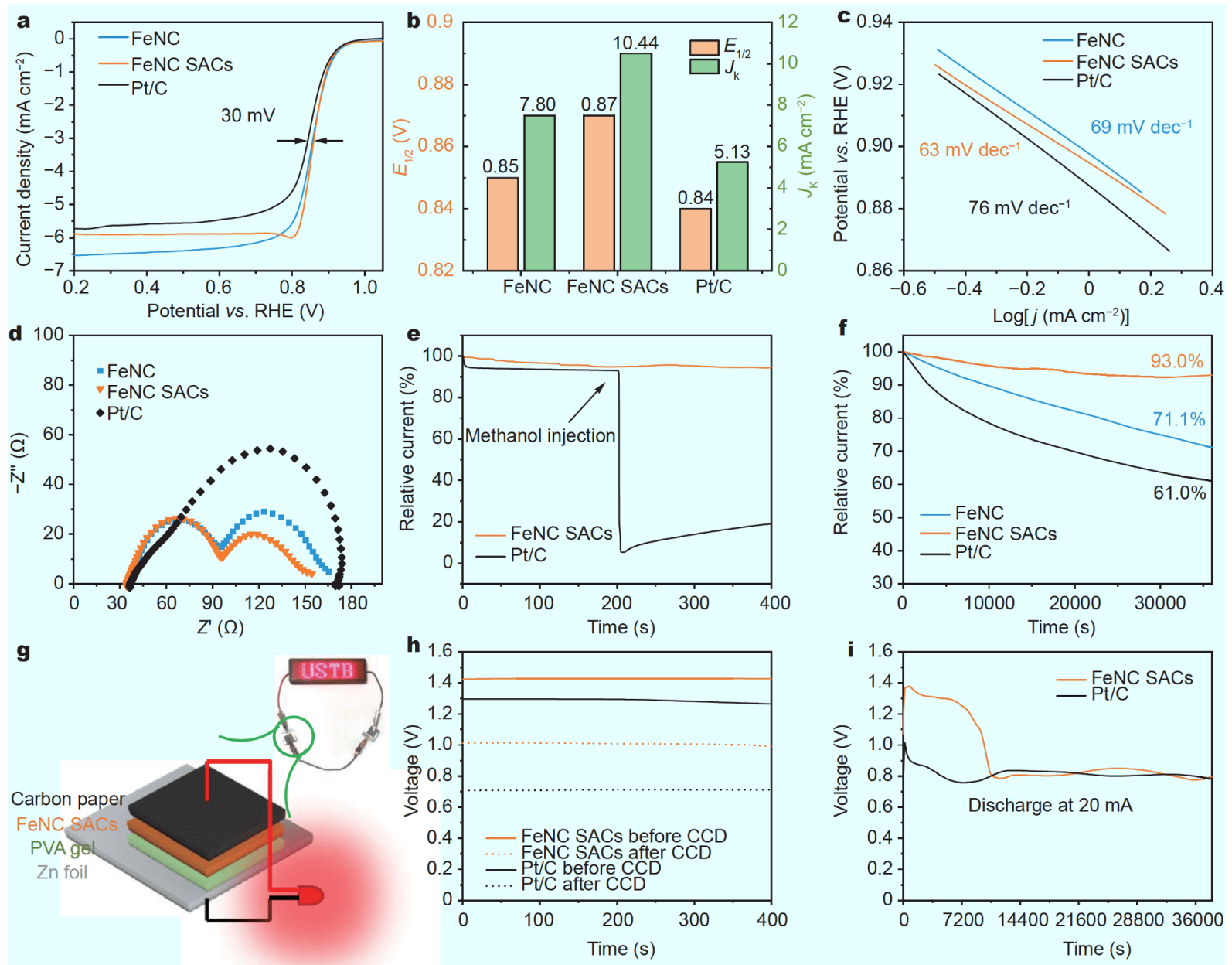

Figure 5 Evaluation of electrochemical performances of FeNC, FeNC SACs, and 20 wt.\% Pt/C catalysts. (a) LSV curves; (b) comparison of the halfwave potential $\left(E_{1 / 2}\right)$ and kinetic current density $\left(J_{\mathrm{k}}\right)$; (c) Tafel plots; (d) Nyquist plots obtained by EIS; (e) relative current density-time curves of FeNC SACs and $20 \mathrm{wt} \% \mathrm{Pt} / \mathrm{C}$ catalysts at $0.6 \mathrm{~V}$ with methanol injection; and (f) relative current density-time curves at $0.6 \mathrm{~V}$ for $36,000 \mathrm{~s}(10 \mathrm{~h}$ ). (g) Illustration of a homemade microscale $\mathrm{Zn}$-air battery and photograph of a light board powered by two connected batteries. (h) OCV of a Zn-air battery fabricated using FeNC SACs and commercial Pt/C catalyst as cathode catalysts before (solid lines) and after (dashed lines) the CCD tests. (i) Simulated chronopotentiometry curves of CCD $(20 \mathrm{~mA})$ for practical application.

completed. Video S1 that shows the four steps of electron transfer can be found in Supplementary information.

Fig. $5 \mathrm{c}$ shows the Tafel slopes of the catalysts and the commercial $\mathrm{Pt} / \mathrm{C}$ catalysts. The FeNC SACs have a smaller Tafel slope of $63 \mathrm{mV} \mathrm{dec}^{-1}$ in comparison with those of the FeNC catalysts $\left(69 \mathrm{mV} \mathrm{dec}^{-1}\right)$, the commercial $\mathrm{Pt} / \mathrm{C}$ catalysts $\left(76 \mathrm{mV} \mathrm{dec}^{-1}\right)$, and other catalysts (Fig. S16b), further confirming the prominent ORR activity of the FeNC SACs. Subsequently, electrochemical impedance spectroscopy (EIS) was performed. The FeNC SACs exhibit the smallest interface charge transfer resistance (Fig. 5d and Fig. S16c), indicating the highest kinetic activity of FeNC SACs among the catalysts. Fur- thermore, chronoamperometric response tests were performed to characterize the stability and durability of the synthesized catalysts. As shown in Fig. 5e, the commercial $\mathrm{Pt} / \mathrm{C}$ catalysts exhibit an obvious decay of the current density as methanol is injected into the electrolyte, which is due to the electrochemical oxidation of methanol. By contrast, the FeNC SACs exhibit a much higher selectivity toward the ORR. These results indicate that methanol crossover should not be a concern when the FeNC SACs are incorporated into the cathode for the direct methanol fuel cells. The durability of the catalysts is a crucial parameter associated with their commercial application. Clearly, the durability of FeNC SACs is substantially 
improved by the calcination at $800^{\circ} \mathrm{C}$. The FeNC SACs retain $93.0 \%$ of their relative current density after the chronoamperometric test for $36,000 \mathrm{~s}$ (Fig. 5f), which is much higher than the current densities retained by the FeNC catalysts without calcination (71.1\%) and other catalysts, including the commercial $\mathrm{Pt} / \mathrm{C}(61.0 \%)$, the FeNC H (72.7\%), and the FeNC H4 (57.7\%) (Fig. S16d).

We finally fabricated a homemade microscale $\mathrm{Zn}$-air battery system to evaluate the practical utility of the FeNC SACs. The Zn-air battery consists of a $\mathrm{Zn}$ foil anode, solid $\mathrm{KOH}-$ poly(vinyl alcohol) (PVA) electrolyte, and a carbon-paper-supported FeNC SAC cathode (Fig. 5g). Two homemade Zn-air batteries could power a red lightemitting diode (LED) board. The FeNC SAC-catalyzed battery operated with an open-circuit voltage (OCV) of $1.43 \mathrm{~V}$ (Fig. 5h), which is higher than that of Pt/C catalysts $(1.30 \mathrm{~V})$, and most reported noble metal-free electrocatalysts (Table S4). To simulate a practical application, a constant-current discharge (CCD, $20 \mathrm{~mA}$ ) test was carried out (Fig. 5i). After $4600 \mathrm{~s}$, the voltage of the $\mathrm{Pt} / \mathrm{C}$-catalyzed battery decayed to $0.8 \mathrm{~V}$. However, surprisingly, the voltage of the FeNC SAC-catalyzed battery did not decay to $0.8 \mathrm{~V}$ until $11,000 \mathrm{~s}$. The FeNC SAC-catalyzed battery discharged $75.4 \mathrm{~mW} \mathrm{~h}$ $(61.1 \mathrm{~mA} \mathrm{~h})$ of power, whereas the $\mathrm{Pt} / \mathrm{C}$-catalyzed battery discharged $22.2 \mathrm{~mW} \mathrm{~h}(25.6 \mathrm{~mA} \mathrm{~h})$ of power before the voltage decayed to $0.8 \mathrm{~V}$. Notably, however, the FeNC SAC-catalyzed battery regained an OCV of $1.0 \mathrm{~V}$ from $0.8 \mathrm{~V}$ after the CCD experiment (Fig. 5g), possibly indicating that its recharge ability is substantially better than that of the commercial $\mathrm{Pt} / \mathrm{C}$-catalyzed battery $(0.7 \mathrm{~V})$. The electrochemical and battery tests demonstrate that the FeNC SACs perform much better than the commercial $\mathrm{Pt} / \mathrm{C}$ catalysts in terms of activity, stability, and durability. This type of FeNC catalyst, which is inexpensive and can be easily synthesized at large scale, exhibits good prospects for use in metal-air batteries, direct methanol fuel cells, and hydrogen fuel cells.

\section{CONCLUSION}

Mass production of FeNC SACs with atomically dispersed active sites was successfully realized using a simple but effective strategy by combining the ultrasonic atomization with the subsequent pyrolysis and calcination processes. Single Fe atoms chelating with four $\mathrm{N}$ atoms, which can be stably anchored onto the CB surface, are confirmed to be the active centers through various analyses of the catalysts' microstructures, components, and electronic states, together with analyses and comparisons of several physical and electrochemical properties. The formed golf-ball-like rough surface of $\mathrm{CB}$ with atomically dispersed active sites provides ample reactive contact area, leading to enhanced ORR catalytic activity and enhanced activity of the prepared cathode. The acid leaching and the calcination at $800^{\circ} \mathrm{C}$ considerably improve the durability of the FeNC SACs. Furthermore, Zn-air batteries fabricated with the FeNC SACs as cathode catalysts demonstrate their considerable potential applications. The FeNC SACs are superior to commercial Pt/C catalysts in terms of their cost and electrochemical catalytic performance. This study not only provides a simple general novel strategy for the synthesis of SACs at large scale but also holds great promise for industrial application in fuel cells and batteries. Results related to the largescale syntheses of other types of highly efficient SACs on different supports will be demonstrated in our future studies, together with detailed analyses of their microstructures and catalytic performances.

Received 7 May 2020; accepted 17 July 2020;

published online 30 September 2020

1 Stamenkovic VR, Strmcnik D, Lopes PP, et al. Energy and fuels from electrochemical interfaces. Nat Mater, 2016, 16: 57-69

2 Chu S, Cui Y, Liu N. The path towards sustainable energy. Nat Mater, 2016, 16: 16-22

3 Chen Y, Ji S, Zhao S, et al. Enhanced oxygen reduction with singleatomic-site iron catalysts for a zinc-air battery and hydrogen-air fuel cell. Nat Commun, 2018, 9: 5422

4 Tiwari JN, Tiwari RN, Singh G, et al. Recent progress in the development of anode and cathode catalysts for direct methanol fuel cells. Nano Energy, 2013, 2: 553-578

5 Shao M, Chang Q, Dodelet JP, et al. Recent advances in electrocatalysts for oxygen reduction reaction. Chem Rev, 2016, 116: 3594-3657

6 Mori K, Sano T, Kobayashi $\mathrm{H}$, et al. Surface engineering of a supported PdAg catalyst for hydrogenation of $\mathrm{CO}_{2}$ to formic acid: Elucidating the active Pd atoms in alloy nanoparticles. J Am Chem Soc, 2018, 140: 8902-8909

7 Yan Z, He G, Shen PK, et al. MoC-graphite composite as a Pt electrocatalyst support for highly active methanol oxidation and oxygen reduction reaction. J Mater Chem A, 2014, 2: 4014

8 Nie Y, Li L, Wei Z. Recent advancements in Pt and Pt-free catalysts for oxygen reduction reaction. Chem Soc Rev, 2015, 44: 2168-2201

9 Ma J, Tong X, Wang J, et al. Rare-earth metal oxide hybridized $\mathrm{PtFe}$ nanocrystals synthesized via microfluidic process for enhanced electrochemical catalytic performance. Electrochim Acta, 2019, 299: 80-88

$10 \mathrm{Xu} \mathrm{Q}$, Guo CX, Tian S, et al. Coordination structure dominated performance of single-atomic Pt catalyst for anti-Markovnikov hydroboration of alkenes. Sci China Mater, 2020, 63: 972-981

11 Garçon M, Bakewell C, Sackman GA, et al. A hexagonal planar transition-metal complex. Nature, 2019, 574: 390-393

12 Song Y, Hart KT, Dooley KM. Waste-reducing catalytic oxidation of $m$-xylene to $m$-toluic acid. Catal Lett, 2016, 146: 1213-1220

13 Song Y, Hart KT, Dooley KM. Waste-reducing catalysis for acy- 
lation of a secondary amine: Synthesis of deet. Catal Lett, 2004, 98: 69-75

14 Jasinski R. A new fuel cell cathode catalyst. Nature, 1964, 201: $1212-1213$

15 Huang $\mathrm{K}$, Zhang $\mathrm{L}, \mathrm{Xu} \mathrm{T}$, et al. $-60^{\circ} \mathrm{C}$ solution synthesis of atomically dispersed cobalt electrocatalyst with superior performance. Nat Commun, 2019, 10: 606

16 Liu X, Wang L, Yu P, et al. A stable bifunctional catalyst for rechargeable zinc-air batteries: Iron-cobalt nanoparticles embedded in a nitrogen-doped 3D carbon matrix. Angew Chem Int Ed, 2018, 57: 16166-16170

17 Huang $\mathrm{X}$, Zhang $\mathrm{Y}$, Shen $\mathrm{H}$, et al. $\mathrm{N}$-doped carbon nanosheet networks with favorable active sites triggered by metal nanoparticles as bifunctional oxygen electrocatalysts. ACS Energy Lett, 2018, 3: 2914-2920

18 Sun $\mathrm{T}, \mathrm{Tian} \mathrm{B}, \mathrm{Lu}$ J, et al. Recent advances in $\mathrm{Fe}$ (or Co)/N/C electrocatalysts for the oxygen reduction reaction in polymer electrolyte membrane fuel cells. J Mater Chem A, 2017, 5: 1893318950

19 Wang D, Astruc D. The recent development of efficient earthabundant transition-metal nanocatalysts. Chem Soc Rev, 2017, 46: 816-854

20 Leonard ND, Wagner S, Luo F, et al. Deconvolution of utilization, site density, and turnover frequency of Fe-nitrogen-carbon oxygen reduction reaction catalysts prepared with secondary $\mathrm{N}$-precursors. ACS Catal, 2018, 8: 1640-1647

21 Ren J, Antonietti M, Fellinger TP. Efficient water splitting using a simple Ni/N/C paper electrocatalyst. Adv Energy Mater, 2015, 5: 1401660

22 Jiang WJ, Gu L, Li L, et al. Understanding the high activity of Fe$\mathrm{N}-\mathrm{C}$ electrocatalysts in oxygen reduction: $\mathrm{Fe} / \mathrm{Fe}_{3} \mathrm{C}$ nanoparticles boost the activity of Fe- $\mathrm{N}_{x}$. J Am Chem Soc, 2016, 138: 3570-3578

23 Kim SJ, Mahmood J, Kim C, et al. Defect-free encapsulation of $\mathrm{Fe}^{0}$ in $2 \mathrm{D}$ fused organic networks as a durable oxygen reduction electrocatalyst. J Am Chem Soc, 2018, 140: 1737-1742

24 Kramm UI, Herrmann-Geppert I, Behrends J, et al. On an easy way to prepare metal-nitrogen doped carbon with exclusive presence of $\mathrm{MeN}_{4}$-type sites active for the ORR. J Am Chem Soc, 2016, 138: 635-640

$25 \mathrm{Xu} \mathrm{H}$, Cheng D, Cao D, et al. A universal principle for a rational design of single-atom electrocatalysts. Nat Catal, 2018, 1: 339-348

26 Pan Y, Lin R, Chen Y, et al. Design of single-atom Co- $\mathrm{N}_{5}$ catalytic site: A robust electrocatalyst for $\mathrm{CO}_{2}$ reduction with nearly $100 \%$ CO selectivity and remarkable stability. J Am Chem Soc, 2018, 140: 4218-4221

27 Yang Z, Chen B, Chen W, et al. Directly transforming copper (I) oxide bulk into isolated single-atom copper sites catalyst through gas-transport approach. Nat Commun, 2019, 10: 3734

$28 \mathrm{He} \mathrm{X}, \mathrm{He} \mathrm{Q}$, Deng Y, et al. A versatile route to fabricate single atom catalysts with high chemoselectivity and regioselectivity in hydrogenation. Nat Commun, 2019, 10: 3663

29 Chen Y, Li Z, Zhu Y, et al. Atomic Fe dispersed on N-doped carbon hollow nanospheres for high-efficiency electrocatalytic oxygen reduction. Adv Mater, 2019, 31: 1806312

30 Liu P, Zhao Y, Qin R, et al. Photochemical route for synthesizing atomically dispersed palladium catalysts. Science, 2016, 352: 797800

31 Han X, Ling X, Wang Y, et al. Generation of nanoparticle, atomiccluster, and single-atom cobalt catalysts from zeolitic imidazole frameworks by spatial isolation and their use in zinc-air batteries.
Angew Chem Int Ed, 2019, 58: 5359-5364

32 Tian X, Lu XF, Xia BY, et al. Advanced electrocatalysts for the oxygen reduction reaction in energy conversion technologies. Joule, 2020, 4: 45-68

33 Ruggeri S, Dodelet JP. Influence of structural properties of pristine carbon blacks on activity of $\mathrm{Fe} / \mathrm{N} / \mathrm{C}$ cathode catalysts for PEFCs. J Electrochem Soc, 2007, 154: B761

34 Zhang Z, Sun J, Wang F, et al. Efficient oxygen reduction reaction (ORR) catalysts based on single iron atoms dispersed on a hierarchically structured porous carbon framework. Angew Chem Int Ed, 2018, 57: 9038-9043

35 Lin Y, Liu P, Velasco E, et al. Fabricating single-atom catalysts from chelating metal in open frameworks. Adv Mater, 2019, 31: 1808193

36 Cao R, Thapa R, Kim H, et al. Promotion of oxygen reduction by a bio-inspired tethered iron phthalocyanine carbon nanotube-based catalyst. Nat Commun, 2013, 4: 2076

37 Wang $\mathrm{H}$, Maiyalagan $\mathrm{T}$, Wang $\mathrm{X}$. Review on recent progress in nitrogen-doped graphene: Synthesis, characterization, and its potential applications. ACS Catal, 2012, 2: 781-794

38 Mun Y, Kim MJ, Park SA, et al. Soft-template synthesis of mesoporous non-precious metal catalyst with $\mathrm{Fe}-\mathrm{N}-\mathrm{X} / \mathrm{C}$ active sites for oxygen reduction reaction in fuel cells. Appl Catal B-Environ, 2018, 222: 191-199

39 Mun Y, Lee S, Kim K, et al. Versatile strategy for tuning ORR activity of a single $\mathrm{Fe}-\mathrm{N}_{4}$ site by controlling electron-withdrawing/ donating properties of a carbon plane. J Am Chem Soc, 2019, 141: 6254-6262

40 Wang J, Wang Z, Li S, et al. Surface and interface engineering of $\mathrm{FePt} / \mathrm{C}$ nanocatalysts for electro-catalytic methanol oxidation: Enhanced activity and durability. Nanoscale, 2017, 9: 4066-4075

41 Cao L, Liu W, Luo Q, et al. Atomically dispersed iron hydroxide anchored on Pt for preferential oxidation of $\mathrm{CO}$ in $\mathrm{H}_{2}$. Nature, 2019, 565: 631-635

42 Zitolo A, Goellner V, Armel V, et al. Identification of catalytic sites for oxygen reduction in iron- and nitrogen-doped graphene materials. Nat Mater, 2015, 14: 937-942

43 Wan X, Liu X, Li Y, et al. Fe-N-C electrocatalyst with dense active sites and efficient mass transport for high-performance proton exchange membrane fuel cells. Nat Catal, 2019, 2: 259-268

44 Lai Q, Zheng L, Liang Y, et al. Metal-organic-framework-derived $\mathrm{Fe}-\mathrm{N} / \mathrm{C}$ electrocatalyst with five-coordinated $\mathrm{Fe}-\mathrm{N}_{x}$ sites for advanced oxygen reduction in acid media. ACS Catal, 2017, 7: 16551663

45 Kramm UI, Herranz J, Larouche N, et al. Structure of the catalytic sites in Fe/N/C-catalysts for $\mathrm{O}_{2}$-reduction in pem fuel cells. Phys Chem Chem Phys, 2012, 14: 11673-11688

46 Jia Q, Ramaswamy N, Tylus U, et al. Spectroscopic insights into the nature of active sites in iron-nitrogen-carbon electrocatalysts for oxygen reduction in acid. Nano Energy, 2016, 29: 65-82

47 Walker FA, Simonis U. Iron porphyrin chemistry. Secondary Iron Porphyrin Chemistry. San Francisco: John Wiley \& Sons, Ltd., 2006

48 Crabtree RH. The Organometallic Chemistry of the Transition Metals. 4th ed. Chichester: John Wiley \& Sons, Inc., 2005

49 Sa YJ, Seo DJ, Woo J, et al. A general approach to preferential formation of active $\mathrm{Fe}-\mathrm{N}_{x}$ sites in $\mathrm{Fe}-\mathrm{N} / \mathrm{C}$ electrocatalysts for efficient oxygen reduction reaction. J Am Chem Soc, 2016, 138: 15046-15056

50 Sougrati MT, Goellner V, Schuppert AK, et al. Probing active sites 
in iron-based catalysts for oxygen electro-reduction: A temperature-dependent ${ }^{57} \mathrm{Fe}$ Mössbauer spectroscopy study. Catal Today, 2016, 262: 110-120

51 Masa J, Batchelor-McAuley C, Schuhmann W, et al. KouteckyLevich analysis applied to nanoparticle modified rotating disk electrodes: Electrocatalysis or misinterpretation. Nano Res, 2013, 7: $71-78$

52 Zhou R, Zheng Y, Jaroniec M, et al. Determination of the electron transfer number for the oxygen reduction reaction: From theory to experiment. ACS Catal, 2016, 6: 4720-4728

53 Guo D, Shibuya R, Akiba C, et al. Active sites of nitrogen-doped carbon materials for oxygen reduction reaction clarified using model catalysts. Science, 2016, 351: 361-365

54 Lai L, Potts JR, Zhan D, et al. Exploration of the active center structure of nitrogen-doped graphene-based catalysts for oxygen reduction reaction. Energy Environ Sci, 2012, 5: 7936

Acknowledgements This work was supported by the National Natural Science Foundation of China (NSFC, 51971029), the NSFC-BRICS STI Framework Program (51861145309), the National S\&T Major Project (2018ZX10301201), the Joint Research Project of University of Science and Technology Beijing \& Taipei University of Technology (TW2018007), the "1125" Zhihui Zhengzhou Talent Project of Henan Province (39080070), the Fundamental Research Funds for the Central Universities (FRF-BR-15-027A). Yujun Song also appreciates the fund supports from the "100 talent plan" fund of Fujian province (Contract No: 2017-802). This research used 9-BM beamline at the Advanced Photon Source, a U.S. Department of Energy (DOE) Office of Science User Facility operated for the DOE Office of Science by Argonne National Laboratory under Contract No. DE-AC02-06CH11357. Yujun Song appreciates Dr. Zhang from ZKKF (Beijing) Science \& Technology Co., Ltd., for the HAADF-STEM characterization.

Author contributions Song Y designed the project, engineered the SAC samples, and discussed with Deng Y. Song Y and Wu T designed the experiment of the XAS characterization of SACs. Ma J performed the catalyst preparation and the characterization of the related microstructure and catalytic performance. Wu T and Wang $\mathrm{L}$ conducted the EXAFS and XANES experiments. Ma J and Wang $\mathrm{L}$ wrote the paper, revised by Song Y, Deng Y and Zhang W. All authors took part in the data analysis.

Conflict of interest The authors declare that they have no conflict of interest.

Supplementary information Experimental details and supporting data are available in the online version of the paper.

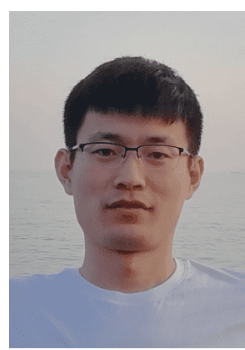

Jugang $\mathrm{Ma}$ is currently a $\mathrm{PhD}$ student at the University of Science and Technology Beijing (USTB) under the direction of Prof. Yujun Song. His main research interests are focused on electrocatalyst synthesis and the related application in fuel cells.

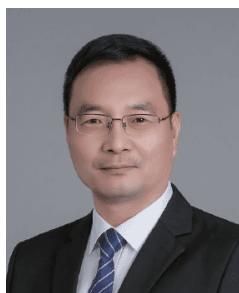

Yujun Song has been a full Professor in physics and applied physics at the USTB, Deputy director of the Center for Modern Physics Research since 2014. His research interests are currently focused on micro/nano-material-mediated integration innovation of modern physics with biomedical engineering, new energy and catalysis, and information science and technology.

\section{通过顺序超声雾化和热解法规模化制备高效单原} 子铁氮碳电催化剂

马炬刚 ${ }^{1}$, 王利光 ${ }^{2}$, 邓意达 ${ }^{3}$, 张伟伟 ${ }^{1}$, 吴天品 ${ }^{2^{*}}$, 宋玉军 ${ }^{1^{*}}$

摘要 燃料电池中氧还原反应 $(O R R)$ 目前面临的主要挑战是如何 大规模生产高效、耐用、廉价的单原子催化剂. 针对这个问题, 我 们开发了一种通用的策略, 即利用简单的超声雾化耦合热解和煅 烧过程来大规模合成单原子FeNC催化剂(FeNC SACs)。通过微观 结构表征发现, 活性中心位于与四吡啶 $\mathrm{N}$ 原子鳌合的单原子 $\mathrm{Fe}$ 位 点. 具有特定可识别的、不同价态的 $\mathrm{Fe}$ 活性位点促进了电子的转 移, 使FeNC SACs具有良好的电化学ORR活性. FeNC SACs被用作 自制的锌空气电池阴极催化剂时, 其开路电压为 $1.43 \mathrm{~V}$, 远高于商 业 $\mathrm{Pt} / \mathrm{C}$ 催化剂. 本研究为大规模合成单原子催化剂提供了一种简单 有效的方法. 